\title{
Productivity Strategies Ranking of Knowledge Workers
}

\author{
${ }^{1}$ ASADALLAH NAJAFI; ${ }^{2}$ ABBAS AFRAZEH \\ ${ }^{I}$ Department of Industrial Engineering (I.E.), Islamic Azad University- Zanjan Branch, Moallem Ave., Zanjan, Iran, \\ asad.najafi@gmail.com \\ ${ }^{2}$ Department of Industrial Engineering (I.E.), Amirkabir University of Technology, Hafez Ave., P.O. Box 15875-4413, Tehran, Iran, \\ afrazeh@aut.ac.ir
}

\begin{abstract}
It is commonly recognized that knowledge is the only source of core competence in the knowledge based companies, but the productivity rate of Knowledge Workers is always Low. Based on Knowledge Workers' characteristics, in this paper, we seek to identify factors influencing the Productivity of Knowledge Workers, and then strategies present for improvement of theirs Productivity. Finally, the best strategy selects using the Fuzzy Analytical Network Process (FANP) approach. It is hoped that this paper will help managers to implement different corresponding measures. Three case studies are presented where this model measure and validates at the Alupan \& Mobarakeh Steel and irancell companies. @ JASEM
\end{abstract}

Productivity is a key determinant for the success of any organization. Work on the productivity of knowledge workers has barely begun: in 2000, the field was roughly in the same place as the study on the productivity of manual workers was in 1950 (Drucker, 1999). In the past, organization success has been analyzed based on three main factors, including cost, time and performance (Afrazeh et al., 2003). One of the fundamental problems of the past approach is lack of attention to other aspects of the Knowledge Workers (Najafi, 2010). Knowledge Workers involved in intellectual will spend more resources. Knowledge Workers are obviously nonmanual workers and are usually employed by organizational managers to carry out innovative activities. Knowledge Worker is a member of the project organization who uses knowledge to be a more productive worker (Najafi and Afrazeh, 2010). Organizational managers that aims to continually improvement in organization, they should be consider the Knowledge Workers' factors as a part of the management process and as a strategic element in organizations. We use the Fuzzy Analytical Network Process (FANP).

\section{MATERIALS AND METHODS}

It was decided to adopt a case study approach for this paper as there is little existing research on analysis of Knowledge Workers factors. It has been based on the descriptive Research. This descriptive type research has been carried out using the questionnaire as the research tool for gathering the required data. Data's gathering involved both reference material and a questionnaire survey. Sampling was simple random sampling and the data gathering instrument was the questionnaire. The author had already undertaken research in this field, which had stimulated the ranking tools and the theoretical framework used to analyze this case study, based on FANP Method. In November 2006 a request for interviews and questionnaires was sent to a number of the strategic managers (60 persons, 40\% Male and 60\% Female, $65 \%$ over 15 year's experience) and strategic staff (60 persons, 35\% Male and 65\% Female, 65\% over 20 year's experience) in the Alupan, strategic managers (80 persons, 50\% Male and 50\% Female, $80 \%$ over 15 year's experience) and strategic staff (60 persons, $70 \%$ Male and 30\% Female, 55\% over 20 year's experience) in the Mobarakeh Steel and strategic managers (100 persons, 60\% Male and 40\% Female, $70 \%$ over 15 year's experience) and strategic staff (90 persons, 35\% Male and 65\% Female, 65\% over 20 year's experience) in the irancell company. Prior to the interview and fill the questionnaire, the author explained the purpose of the research and made it clear that this information would be in the public domain, so any confidentiality concerns could be noted. The interview and questionnaire, from December 2007 to April 2009, lasted ten hours per week. Knowledge Worker factors are achieved in six steps of knowledge management (see appendix 1).

The FANP method is derived as follows:

Step 1: Determine the element sub-factors and strategic options.

Step 2: Establish the Triangular Fuzzy Numbers.

Step 3: Assume that no dependencies among element factors exist, and then the importance degree of factors is shown by the fuzzy scale. 
Step 4: Determine the factors of the internally dependent matrix by the fuzzy scale, and consider other factors by schematic view and internal dependencies among them (W2 calculation)

$w_{\text {factors }}=W_{2} \times w_{1}$

Step 5: Specify the internal dependencies' priorities, that is, calculate

Step 6: Specify the importance degree of sub-factors by fuzzy scale.

Step 7: Specify the importance degree of sub-factors.
Step 8: Specify the importance degree of strategic options, considering each sub-factor, on the fuzzy scale.

Step 9: Calculate the final priority of strategic options derived from the internal relationships among element factors and Defuzzification its.

\section{RESULTS AND DISCUSSION}

Case 1- Alupan

Step 1: First, the issue is depicted as a hierarchical structure, which contains the strategic options and sub-factors for the next calculations using FANP (Fig. 1).

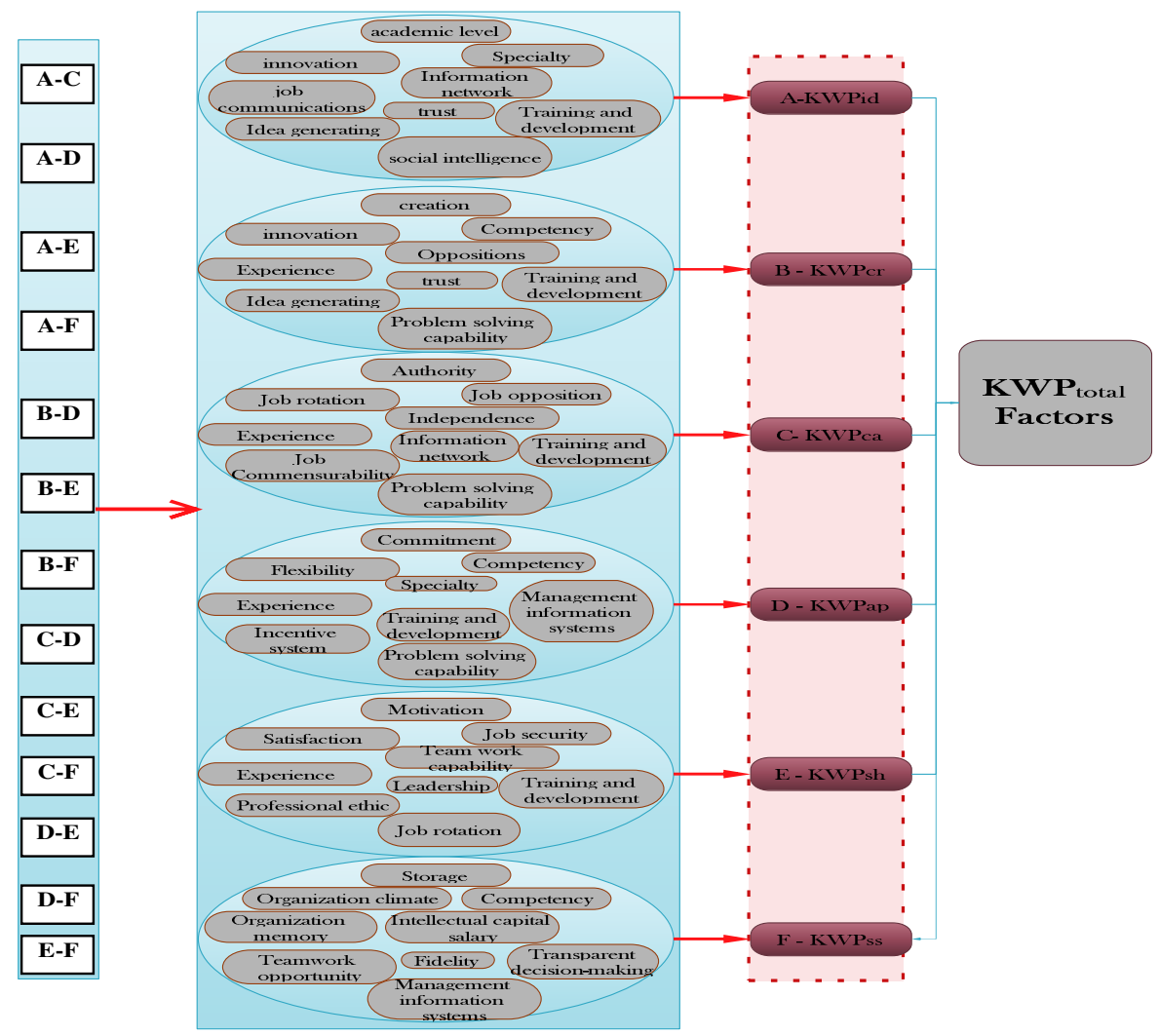

Fig 1: knowledge workers factors and strategies

Step 2: A triangular fuzzy number (TFN) is shown in Fig 2.

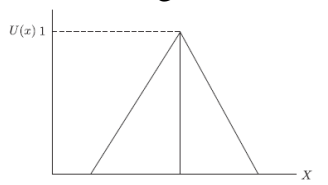

Fig 2: Triangular Fuzzy Numbers 
Since each number in the pair-wise comparison matrix represents the subjective opinion of decision makers and is an ambiguous concept, fuzzy numbers work best to consolidate fragmented expert opinions. A TFN is denoted simply as (L, M, U). The parameters $\mathrm{L}, \mathrm{M}$ and $\mathrm{U}$, respectively, denote the smallest possible value, the most promising value and the largest possible value that describe a fuzzy event as shows in formulae (1) to (5). The triangular fuzzy numbers uij are established as follows:

$\sim$ uij $=(\mathrm{Lij}, \mathrm{Mij}, \mathrm{Uij}) \quad(\mathbf{1}), \mathrm{Lij} \leq \mathrm{Mij} \leq \mathrm{Uij}$ and $\mathrm{Lij}, \mathrm{Mij}$ ,Uij $\varepsilon(1 / 9,9)(2)$

$\mathrm{Lij}=\min (\mathrm{Bijk})(\mathbf{3}), \mathrm{Mij}={ }^{\mathrm{n}} \sqrt{\prod} \operatorname{Bijk}(\mathbf{4})$ and $\mathrm{Uij}=$ $\max (\mathrm{Bijk})(\mathbf{5})$

Where Bijk represents a judgment of expert $\mathrm{k}$ for the relative importance of two criteria $\mathrm{Ci}-\mathrm{Cj}$.

Step 3: Assume that there is no dependency among the element factors. Determine the factors' pair comparison matrix using the numerical scale of 1 to 9.

$$
W_{1}=\left[\begin{array}{c}
A \\
B \\
C \\
D \\
E \\
F
\end{array}\right]=\left[\begin{array}{l}
.366 \\
.231 \\
.170 \\
.114 \\
.078 \\
.041
\end{array}\right]
$$

Step 4: An analysis of internal and external environment elements reveals the element factors' dependencies as shown in Figure 2.

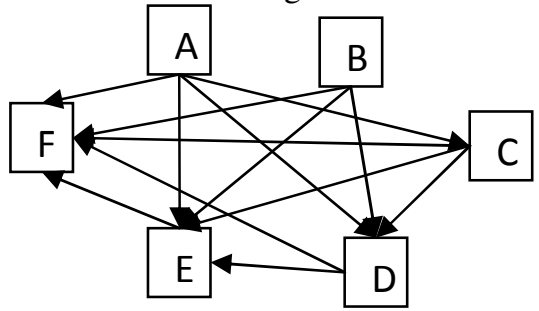

Fig 3: Internal dependency of factors Internal dependency matrix of factors is defined in Table 1.

Table 1: Internal dependency matrix of factor A, B, C, D, E and F

\begin{tabular}{|c|c|c|c|c|c|}
\hline $\begin{array}{c}\text { Weights } \\
\text { of } A\end{array}$ & $\begin{array}{c}\text { Weights } \\
\text { of } B\end{array}$ & $\begin{array}{c}\text { Weights } \\
\text { of } C\end{array}$ & $\begin{array}{c}\text { Weights } \\
\text { of } D\end{array}$ & $\begin{array}{c}\text { Weights } \\
\text { of } E\end{array}$ & $\begin{array}{c}\text { Weights } \\
\text { of } F\end{array}$ \\
\hline .530 & .055 & .565 & .440 & .422 & .490 \\
\hline .310 & .173 & .056 & .307 & .329 & .249 \\
\hline .117 & .772 & .089 & .029 & .039 & .042 \\
\hline \hline .042 & & .290 & .067 & .078 & .081 \\
\hline \hline & & .157 & .131 & .138 \\
\hline \hline
\end{tabular}

$$
w_{\text {factors } w}=W_{2} * W_{1}=\left[\begin{array}{cccccc}
1 & 0 & .565 & .44 & .422 & .490 \\
0 & 1 & 0 & .307 & .329 & .249 \\
.53 & 0 & 1 & .029 & .039 & .042 \\
.31 & .055 & .056 & 1 & .078 & .081 \\
.117 & .173 & .089 & .067 & 1 & .138 \\
.042 & .772 & .290 & .157 & .131 & 1
\end{array}\right] *\left[\begin{array}{c}
.366 \\
.231 \\
.170 \\
.114 \\
.078 \\
.041
\end{array}\right]=\left[\begin{array}{c}
.565 \\
.302 \\
.372 \\
.260 \\
.189 \\
.312
\end{array}\right]
$$

Step 5: Factor priority results including A, B, C, D, E and $\mathrm{F}$ have changed from 0.366 to 0.565 , from 0.231 to 0.302 , from 0.17 to 0.372 , from 0.114 to 0.260 , from 0.078 to 0.189 and from 0.041 to 0.312 .

Step 6: Local priorities of sub-factors are calculated using the pair comparisons matrix. The priority vector is defined. According the priorities, it defines vector of sub factors.
Step 7: General priorities of the element sub-factors are calculated by multiplying the internal dependency priorities, obtained in Step 4, by the local priorities of element sub-factors, obtained in Step 5. The results are depicted. Vector $w_{\text {sub-factors(global) }}$ which is obtained from the general priority amounts in the last column of the local priorities of element sub-factors.

Step 8: The degree of strategic options' importance is calculated from each element's sub-factor 
viewpoints. Special vectors are calculated from the analysis of this matrix and matrix W4.

Step 9: Finally, the general priorities of strategic options are calculated considering the internal dependencies of element factors and defuzzification its, as follows:

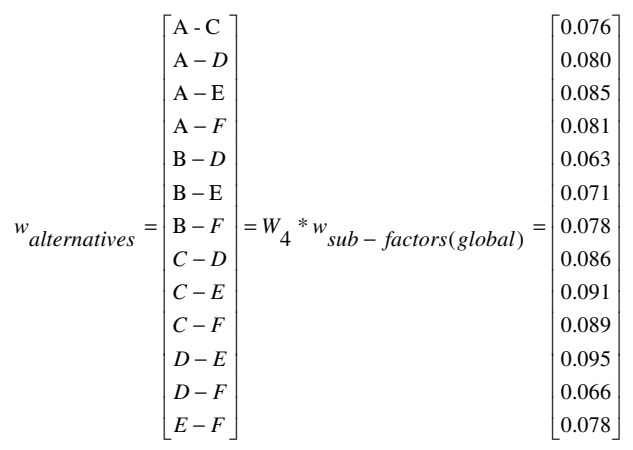

The results of FANP analysis show that the most important strategy for Knowledge Worker Productivity is strategy C-E whose score is 0.091 .

Case 2-Irancell: The results of the FANP analysis show that the most important strategy for Knowledge Worker Productivity is the strategy A-F or whose score is 0.085 .

Case 3-Mobarakeh Steel: The results of FANP analysis show that the most important strategy for Knowledge Worker Productivity is strategy A-C whose score is 0.089 .

This method was tested using Cronbach's alpha (its value was more than 83 ); it has been validated by $86 \%$ of the experts, $75 \%$ of the managers, and by company directors. The results showed a questionnaire validity of $91 \%$. Its validity was measured using the Cronbach Alpha Coefficient, which equalled 92. These results indicate the reliability and validity of the research. Inconsistency ratio (CR) is composed of two parameters: inconsistency index (CI) and Random index (RI). The relationship between RI and $\mathrm{n}$ is as follows: RI = $1.98 *((n-2) / n)$. Where 1.75 is the ratio of the average amount of all numbers for $n=3$ until $n=15$, each having been multiplied by $(n-2) / n$. The calculated amount for the inconsistency ratio in FANP should not be less than 0.1 .

Conclusion: We have defined and classified the effective elements of Knowledge Worker for Knowledge Worker Productivity and analysed them using FANP. Consequent to this analysis, we have presented strategies for improving Knowledge Worker factors, which were verified and validated in a case study of The Alupan, Mobarakeh Steel and irancell companies. One possible follow-up is the comparison of the proposed method with other models, such as neuro-fuzzy methods.

Acknowledgement: This work was supported by Islamic Azad University -Zanjan branch and Amirkabir University of Technology, Tehran, Iran.

\section{REFRENCES}

Afrazeh, A. ,Bartsch, H., Hinterhuber, H. , (2003). Csim ,European Series in Industrial Management in Zulch,Human Aspects in Production Management ,Volume6, Shaker Verlag.

Dainoff, M.J., (2009). Can't we all just get along? Some alternative views of the knowledge worker in complex HCI systems. International Journal of Human-Computer Interaction, 25, 328-347.

Drucker.Peter, (1999). Knowledge Worker Productivity: The biggest chalange" California Management Review, Vol.41,No.2, pp. 79-94

Expert Choice, (2000). Expert Choice, Analytical Hierarchy Process (AHP) Software, Version 9.5, Expert Choice, Pittsburg.

Lee.Kun Chang, Lee.Sangjae,Kang.In von, (2004). KMPI: measuring knowledge management performance, Information \& Management.Article in Press.

Najafi A., (2010). Developing Knowledge Management in Strategic Framework of Mabena Model, World Applied Sciences Journal 9 (8): 879-888.

Najafi A., Afrazeh A., (2010). Using Analytical Network Process for Ranking Educational Factors Influencing on Knowledge Worker Productivity, World Applied Sciences Journal 9 (6): 605-618. 